Volume 8

Issue 4 - Cancer Screening

Article 2

10-18-2021

\title{
Patient Perceptions of Using Clinical Decision Support for Cancer Screening and Prevention: "I wouldn't have thought about getting screened without it."
}

\author{
Daniel M. Saman \\ Melissa L. Harry \\ Laura A. Freitag \\ Clayton I. Allen \\ Patrick J. O'Connor \\ JoAnn M. Sperl-Hillen \\ Joseph A. Bianco \\ Anjali R. Truitt \\ Heidi L. Ekstrom \\ Thomas E. Elliott
}

Follow this and additional works at: https://aah.org/jpcrr

Part of the Community Health and Preventive Medicine Commons, Health Services Research Commons, Oncology Commons, Preventive Medicine Commons, and the Primary Care Commons

\section{Recommended Citation}

Saman DM, Harry ML, Freitag LA, Allen CI, O'Connor PJ, Sperl-Hillen JM, Bianco JA, Truitt AR, Ekstrom HL, Elliott TE. Patient perceptions of using clinical decision support for cancer screening and Prevention: "I wouldn't have thought about getting screened without it." J Patient Cent Res Rev. 2021;8:297-306. doi: $10.17294 / 2330-0698.1863$

Published quarterly by Midwest-based health system Advocate Aurora Health and indexed in PubMed Central, the Journal of Patient-Centered Research and Reviews (JPCRR) is an open access, peer-reviewed medical journal focused on disseminating scholarly works devoted to improving patient-centered care practices, health outcomes, and the patient experience. 


\title{
Patient Perceptions of Using Clinical Decision Support for Cancer Screening and Prevention: "I wouldn't have thought about getting screened without it."
}

\author{
Daniel M. Saman, DrPH, MPH, ${ }^{1}$ Melissa L. Harry, PhD, MSW, ${ }^{2}$ Laura A. Freitag, BA, ${ }^{2}$ Clayton I. \\ Allen, BS, ${ }^{2}$ Patrick J. O'Connor, MD, MA, MPH, ${ }^{3}$ JoAnn M. Sperl-Hillen, MD, ${ }^{3}$ Joseph A. Bianco, MD, ${ }^{4}$ \\ Anjali R. Truitt, PhD, MPH, ${ }^{3}$ Heidi L. Ekstrom, MA ${ }^{3}$ Thomas E. Elliott, MD ${ }^{3}$ \\ ${ }^{1}$ Nicklaus Children's Health System, Miami, FL; ${ }^{2}$ Essentia Institute of Rural Health, Essentia Health, Duluth, MN; \\ ${ }^{3}$ HealthPartners Institute, HealthPartners, Bloomington, MN; ${ }^{4}$ Essentia Health-Ely Clinic, Ely, MN
}
Purpose
We sought to gain an understanding of cancer prevention and screening perspectives among patients exposed to a clinical decision support (CDS) tool because they were due or overdue for certain cancer screenings or prevention.
Methods
Semi-structured qualitative interviews were conducted with 37 adult patients due or overdue for cancer prevention services in 10 primary care clinics within the same health system. Data were thematically segmented and coded using qualitative content analysis.

Results We identified three themes: 1) The CDS tool had more strengths than weaknesses, with areas for improvement; 2) Many facilitators and barriers to cancer prevention and screening exist; and 3) Discussions and decision-making varied by type of cancer prevention and screening. Almost all participants made positive comments regarding the CDS. Some participants learned new information, reporting the CDS helped them make a decision they otherwise would not have made. Participants who used the tool with their provider had higher self-reported rates of deciding to be screened than those who did not.

Conclusions Learning about patients' perceptions of a CDS tool may increase understanding of how patient-tailored CDS impacts cancer screening and prevention rates. Participants found a personalized CDS tool for cancer screening and prevention in primary care useful and a welcome addition to their visit. However, many providers were not using the tool with eligible patients. (J Patient Cent Res Rev. 2021;8:297-306.)

Keywords cancer screening; cancer prevention; clinical decision support; primary care; qualitative research; decision-making

$\longrightarrow$ ancer is the second most common cause of death in the United States ${ }^{1}$ and one of the costliest diseases. ${ }^{2,3}$ Recommendations exist for cancer prevention and screening based on a body of published efficacy research, including breast, colorectal, lung, and cervical and other human papillomavirus (HPV)-linked cancers. ${ }^{4-10}$ However, for a number of reasons, patients may be unaware of or not follow recommendations. Some patients view cancer screenings as a moral obligation, a habit, or a tradition. ${ }^{11}$ Others cite fear of diagnosis, wasted time and effort, false-positives, practical and

Corresponding author: Melissa L. Harry,

Essentia Institute of Rural Health, 502 E. Second St., Duluth, MN 55805 (Melissa.Harry@EssentiaHealth.org) financial barriers, and lack of understanding as reasons for avoiding screenings. ${ }^{12}$ Research suggests that shared decision-making (SDM) between patients and providers assists patients with making a decision regarding cancer prevention and adhering to a cancer screening plan. ${ }^{13,14}$ While providers may perceive the time required to review decision aids as a barrier to use, ${ }^{15,16}$ research has shown the increased time is marginal. ${ }^{16,17}$ Expending a little more time employing SDM during the decision-making process may improve quality of care. ${ }^{15,16}$ Furthermore, innovative tools like algorithm-based clinical decision support (CDS) may improve the SDM process for patients and providers. ${ }^{17,18}$

CDS tools are programmed into electronic health records, prompting providers when patients are due and providing recommendations tailored to individual patients. ${ }^{18-23} \mathrm{CDS}$ can include decision aids - patient- 
focused materials that research has shown can assist patients with making a decision regarding care that, while recommended, carries both risks and benefits that must be weighed for each individual. ${ }^{17,18,21,24}$ Specifically, when providers use tools like decision aids, patients are more likely to make an informed decision based on credible information with a realistic assessment of associated risks. ${ }^{16}$ Research has demonstrated that provider encouragement to get screened is frequently a facilitator for patients. ${ }^{25,26}$

As noted in previous work, ${ }^{22}$ primary care providers (PCPs) frequently neglect to engage patients in cancer screening decision-making processes. ${ }^{27-30}$ Even with CDS in place and widespread knowledge on the importance of SDM in improving patient health, PCPs have the burdensome task of balancing multiple patient needs within relatively short visits, including ensuring patients are up to date on cancer screenings. ${ }^{19,31,32}$ Consequently, some PCPs may not be utilizing SDM, decision aids, or CDS as expected due to factors like time constraints; thus, it can be difficult to assess the value of SDM in clinical practice. ${ }^{33-35}$

To address this gap in patient care, an algorithm-based CDS tool supported by the Chronic Care Model $^{36}$ was developed by the study team. ${ }^{21-23,31,37}$ This point-of-care, web-based CDS is linked to the electronic health record for use in health systems and uses algorithms to identify evidence-based prevention options that address unmet cancer prevention and screening needs, in addition to unmet cardiovascular needs among diabetic patients and those with high, reversible cardiovascular risk. ${ }^{38,39}$ The CDS targets primary cancer prevention indicators (body mass index of $>25$, HPV vaccination status, tobacco use), which focus on keeping cancer from originating, and secondary cancer prevention, which aims to discover and manage the disease through routine breast, cervical, colorectal, and lung screening. ${ }^{40}$ The CDS tool also provides an efficient workflow for ordering recommended screening tests, medications, and referrals.

\section{Objective and Guiding Research Questions}

Patient experiences are a valuable component within CDSbased studies. However, little research of interviewed patients who were exposed to a personalized CDS tool with cancer screening recommendations immediately following a PCP visit is available. Describing patient experiences with CDS may help with PCP adoption of these tools, if patients find value in them. We conducted patient interviews as part of a clinic-cluster-randomized controlled trial on the CDS to understand how patients perceive and make cancer prevention and screening decisions based on exposure to a personalized CDS tool. Our guiding research questions were 1) How do patients perceive CDS use, recommendations, layout, and content? 2) What are barriers and facilitators to act on personalized cancer recommendations from a patient perspective? and 3) What are patients' perceptions of the value of PCPs in the decision-making process?

\section{METHODS}

\section{Setting and Participants}

The purposive sample in this study included 37 adult ( $\geq 20$ years of age) patients who, based on recommendations, ${ }^{4-10}$ were due or overdue for cancer screening (breast, cervical, colorectal, lung) and/or prevention (HPV vaccination, tobacco use, obesity status) and interested in participating in an interview at their office visit (for any reason). Visits took place in 10 primary care clinics that are part of an integrated health system serving a generally rural population, with study clinic locations in northern Minnesota, eastern North Dakota, and northwestern Wisconsin.

Qualitative semi-structured interviews were conducted within clinics in 2 intervention arms of a 3 -arm (usual care, cancer prevention CDS, cancer prevention CDS plus SDM tools) clinic-randomized trial conducted at the health system..$^{21,23,31}$ In the CDS-only intervention arm, eligible patients could receive a CDS paper handout noting if they were due or overdue for cancer prevention and screening, along with cardiovascular risk items related to another randomized controlled trial. ${ }^{21-23,31}$ In the CDS plus SDM arm, eligible patients could receive both the CDS and patient-forward SDM tools for breast, colorectal, or lung cancer screening or for HPV vaccination..$^{21,23,31}$ The CDS also was available to PCPs electronically in both study arms, with SDM tools available to only PCPs in the CDS plus SDM arm. ${ }^{21,23,31}$ The study team created the SDM tools based on existing literature, expert opinion, and pilot testing..$^{21,23,31}$

Trial follow-up ended October 31, 2020. Intervention clinics were encouraged to achieve an $80 \%$ CDS print rate among eligible patients. Rooming staff handed patients a personally tailored patient printout (Online Supplemental Figure S1) and placed a more detailed PCP version (Online Supplemental Figure S2) on the exam room door. ${ }^{21,23,31}$

\section{Data Collection}

This study was approved by Essentia Health's institutional review board. The semi-structured interview guide and example probing questions are presented in Online Appendix A. Demographics were collected using a form that participants completed after the interview (Online Appendix B). Screening history data were captured by 
study team members reviewing participants' CDS for cancer prevention and screening recommendations.

In person, digitally recorded interviews were conducted from August 14, 2019, to January 22, 2020, by 3 team members (site principal investigator and site project managers) working together in dyads in which one team member led the interview and the other assisted with probing questions. Patients were recruited through an informational flyer distributed by clinic rooming staff during the patient's appointment at each respective clinic. The flyer provided study information and the location of the interview in the clinic. The research team determined eligibility by reviewing patients' CDS printouts.

For eligible patients, a semi-structured interview was conducted with the patient directly after the completion of their medical appointment. Verbal consent was established at the beginning of the interview and reiterated during the interview. Written documentation of informed consent for participants was waived by the Essentia Health institutional review board as the information collected was not considered sensitive. Participants were given a \$20 Visa gift card as a participation incentive. Interviews were conducted in an iterative process along with qualitative coding until thematic data saturation was reached.

\section{Data Analysis}

Digitally recorded interviews were professionally transcribed, error-checked by study team members, de-identified, and thematically segmented for analysis in HyperRESEARCH software (version 4.5.0, Researchware, Inc.). ${ }^{41,42}$ Throughout data collection, our methodological approach included qualitative content analysis and open coding to iteratively develop and apply a coding frame by 2 site project managers, with an investigator providing training on qualitative data analysis, assisting with coding frame development, adjudicating coding differences, ${ }^{42}$ and reporting results. We used a consensus approach wherein we discussed any disagreements on coding until we reached consensus, resulting in 100\% agreement on coded segments.

\section{RESULTS}

All 37 participants described receiving the CDS printout from the rooming nurse or assistant, which was the recommended workflow. Only one individual did not review the CDS printout during their clinic visit; 10 participants received both patient and provider versions, while 27 received the patient version of the CDS. Table 1 presents demographics, visit characteristics, and cancer prevention and screening CDS recommendations for
Table 1. Descriptive Characteristics of Qualitative Interview Participants $(n=37)$ in 10 Study Clinics, August 14, 2019-January 22, 2020

\begin{tabular}{|c|c|}
\hline Descriptive characteristic & n (\%) \\
\hline Female sex & $27(73)$ \\
\hline \multicolumn{2}{|l|}{ Race } \\
\hline African American & $1(3)$ \\
\hline White & $34(92)$ \\
\hline American Indian & $2(5)$ \\
\hline \multicolumn{2}{|l|}{ Educational level } \\
\hline High school graduate or GED & $11(30)$ \\
\hline Some college or 2-year degree & $14(38)$ \\
\hline 4-year college graduate & $5(14)$ \\
\hline More than 4-year college degree & $5(14)$ \\
\hline \multicolumn{2}{|l|}{ Reason for clinic visit } \\
\hline Annual exam visit & $7(19)$ \\
\hline Non-annual exam visit & $30(81)$ \\
\hline \multicolumn{2}{|c|}{ Patients identified by CDS, of those eligible } \\
\hline Breast cancer screening ${ }^{a}$ & 13 of $18(72)$ \\
\hline Cervical cancer screening ${ }^{b}$ & 14 of $22(64)$ \\
\hline Colorectal cancer screening ${ }^{c}$ & 15 of $26(58)$ \\
\hline HPV vaccine ${ }^{d}$ & 4 of $5(80)$ \\
\hline Lung cancer screeninge & 12 of $23(52)$ \\
\hline
\end{tabular}

Note: Recommendations were guided by the U.S. Preventive Services Task Force and others. ${ }^{4-10}$

${ }^{a}$ Breast cancer screening eligibility includes women age 50-75 at average risk or women age 35-49 with a 5-year estimated risk of $>2 \%$ or lifetime estimated risk of $>16.8 \%$, per the Breast Cancer Risk Assessment Tool.

${ }^{b}$ Cervical cancer screening eligibility includes women 21-65 years old.

${ }^{\circ}$ Colorectal cancer screening eligibility includes patients age 18-75 at high risk, age 50-75 not at high risk, or age 40-75 with documented family history or polyps.

${ }^{a} H P V$ vaccine eligibility includes patients 18-26 years old.

e Lung cancer screening eligibility includes patients 55-75 years old.

CDS, clinical decision support; HPV, human papillomavirus.

the 37 study participants. Most participants identified as female $(73 \%)$, White $(92 \%)$, and had at least a high school education (100\%). Median age of the study cohort was 57 years (range: 20-73; mean: 50.8; standard deviation: 16.2). Participants' overdue cancer prevention and screening areas are shown in Table 1.

Three overarching themes emerged from qualitative coding: strengths outweighed weaknesses in participants' perceptions of CDS content; many facilitators and barriers 
to cancer prevention and screening exist; and cancer prevention and screening discussions and decisionmaking vary by type.

\section{Strengths of CDS Content and Opportunities for Improvement}

Most participants described numerous CDS content strengths (Table 2). For example, participants liked the CDS information related to cancer screening and prevention, finding it to be easy to understand: "It's straightforward, easy to read. And I'm actually glad I got it [the CDS] because I wouldn't have thought about going in for screening without it." Participants also reported liking how the CDS aided PCPs and patients in discussing cancer prevention and screening: "It's a good way to open a door to talk to young people my age, men and women, about getting screened for cancer."

Many participants described learning new details related to cancer prevention and screening from the CDS. Some participants described already being aware of the information presented on the CDS: "I kind of had an idea that I was at risk for a few things. " However, participants still found value in the CDS: "It's nothing that I didn't know, but it's nice to have it. Like, I can hang this on my fridge and say, 'Hey, I have to remember to do this,'

Table 2. Clinical Decision Support (CDS) Strengths and Weaknesses Reported by Interviewees $(n=37)$

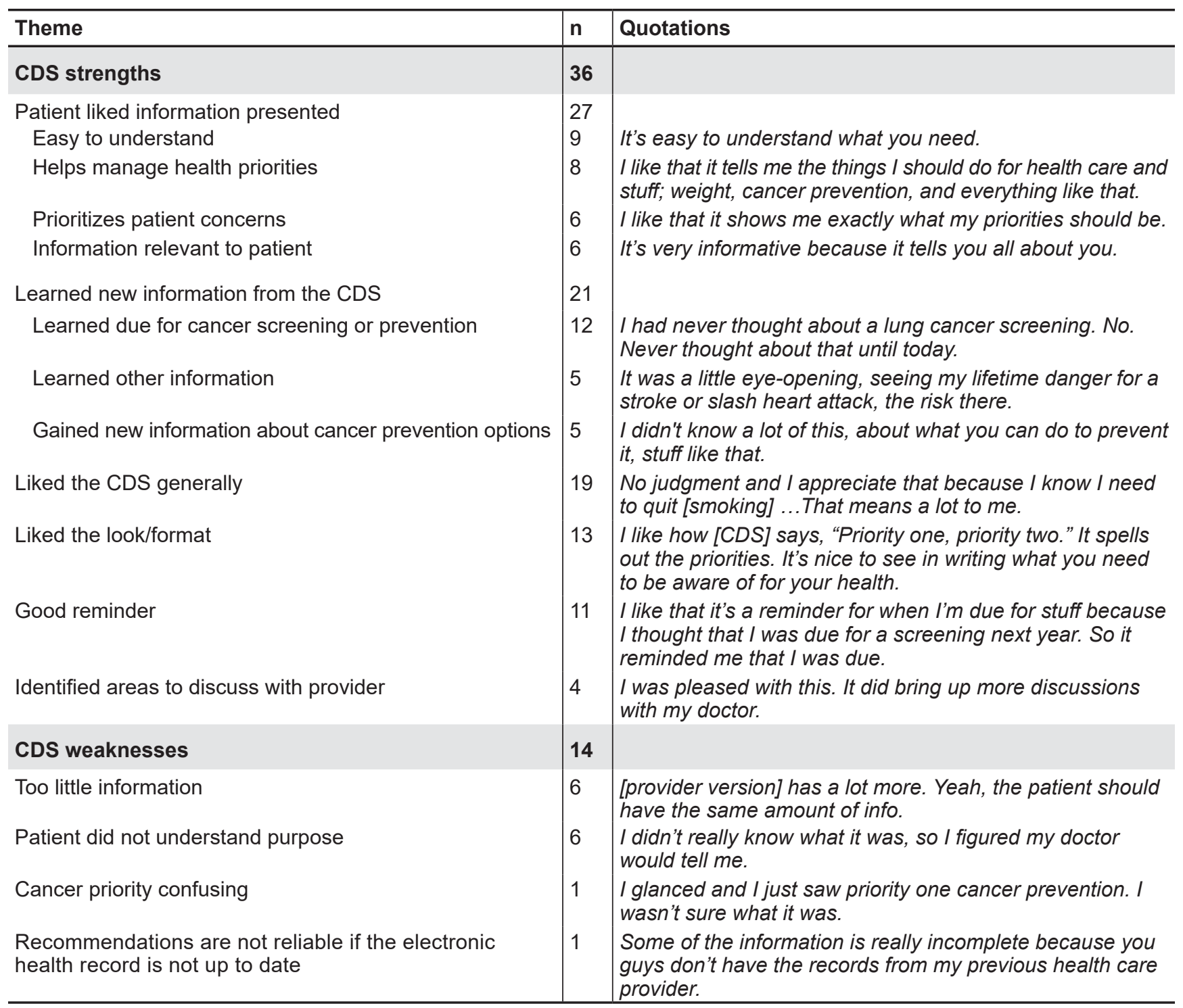

Note: Interviewees could be included under more than one subtheme. 
instead of trying [to] remember to, 'Oh, yeah, I've got to schedule that." Many participants reported liking the CDS generally: "It seemed like a great form just to identify potential issues and highlight them."

The majority of participants could not identify any specific weaknesses of the CDS content for patients (including 1 individual who did not report any CDS content strengths). Of those who noted aspects of the CDS that could be perceived as weaknesses, some were confused by an aspect of the CDS, such as the caution signs. Some participants also thought that the CDS could present more personalized content for patients and required accurate electronic health record data, suggesting areas for CDS improvements (Table 2).

\section{Facilitators and Barriers to Cancer Prevention and Screening at Patient and CDS Levels}

Participants reported a number of facilitators and barriers to cancer prevention and screening (Table 3). At the patient level, personal preferences were a key facilitator for most participants. For example, many participants described wanting to discuss cancer prevention with their PCP. Some talked about the importance of cancer prevention and screening, including both generally and personally: "There are some tests I don't like doing, but I do them because it's the best for my health [laughter] ... Do I like to do [a colonoscopy]? No, but should everybody do it? Yes."

Regarding CDS-level facilitators, some participants reported that the CDS assisted them with deciding on cancer prevention and screening as well as prompted discussions between participants and their PCPs, with some participants noting that the CDS provided a guideline to frame that discussion. The CDS appeared to facilitate discussion of cancer prevention and screening:

Interviewer: "So, I assume cancer prevention wasn't part of your visit today. But did you end up talking about cancer prevention?"

Participant: "Yeah. We did, actually. We went through [the CDS] ... 'Cancer screening due.,'

However, just 17 (46\%) participants reported reviewing the CDS with their PCP.

Many participants noted potential patient-level barriers to cancer screening and prevention (Table 3). Some reported not wanting to talk about cancer prevention and screening: "No, because I got enough going on today." Some participants were simply not concerned about their personal risk, either with or without a family history of cancer. This suggests that PCPs may not be adequately conveying the risks for common cancers to patients that may need screening. Having a negative experience with past cancer screening or HPV vaccination was mentioned as a barrier. Additional patient-level barriers are noted in Table 3.

Regarding CDS-level barriers to cancer prevention and screening, some participants said their PCP did not use the CDS tool during their visit (Table 3). In some cases, this may be due to a PCP's lack of familiarity with the tool; however, other PCPs aware of the CDS chose not to use it in the visit. In other cases, PCPs covered items on the CDS without using the tool or instead focused on the reason for the participant's visit: "She was too busy."

\section{Cancer Prevention and Screening Discussions and Decision-Making May Vary by Type}

Table 4 shows how many of each cancer prevention or screening recommendation were included on the CDS printouts for study participants, whether the recommendation was discussed at the visit, and the decisions made regarding each recommendation. Seven (19\%) participants did not discuss any cancer screening or prevention CDS areas with their PCP during their visit (data not shown in Table 4), in some cases because it fell outside the reason for the visit: "No. It [cancer prevention and screening] was unimportant. I'm pretty sick." Also, while most of those with cancer prevention and screening CDS recommendations discussed those recommendations with their PCP, just 1 of $12(8 \%)$ candidates eligible for lung cancer screening reported discussing this option with their PCP.

Since only HPV vaccinations and Pap tests were able to be performed within the visit, other screenings needed to be scheduled for the majority of participants (Table 4). Some individuals chose to schedule screenings or have a Pap test or HPV vaccination in the office that day. However, aside from cervical cancer screenings, most participants did not decide on screening or prevention options that day. Two individuals were against cancer screening generally, while 2 other individuals declined the HPV vaccine and 1 reported stopping the series: "Well, I had it done. And then because of the [allergic] reaction, I didn't go through with it anymore." Yet, of the 4 participants who reported negative experience with past cancer screening or HPV vaccination, 3 decided to schedule a screening or had a Pap performed the day of interviews.

Some participants expressed conflicted feelings regarding getting screened, which may factor into whether or not scheduled screening will be successfully completed in the future: "[The PCP] told me about [the low-dose CT scan], and I said, 'Yeah, let's do it, 'because I was a smoker for all them years. But it's like, do I want to know?" 
Table 3. Cancer Prevention and Screening Facilitators and Barriers Described by Interviewees $(n=37)$

\begin{tabular}{|c|c|c|}
\hline Themes & $\mathbf{n}$ & Quotations \\
\hline Facilitators & 29 & \\
\hline $\begin{array}{l}\text { Patient level } \\
\text { Wanted to talk about cancer prevention } \\
\text { Personal importance of cancer prevention }\end{array}$ & $\begin{array}{l}28 \\
21 \\
13\end{array}$ & $\begin{array}{l}\text { It's a good thing to discuss. } \\
\text { I find that very actually interesting because it [cancer] is } \\
\text { a topic I was talking to the doctors before she had even } \\
\text { handed me this [the CDS]. So it was dead-on. }\end{array}$ \\
\hline General importance of cancer prevention & 5 & $\begin{array}{l}\text { I think it's great that you're coming up with more programs } \\
\text { to help people to be more aware [of cancer]. I think you'll } \\
\text { help people greatly and save a lot of lives. }\end{array}$ \\
\hline Comfortable discussing cancer prevention & 13 & $\begin{array}{l}\text { I think it should be able to be discussed openly and freely } \\
\text { and without bias because, I mean, it's cancer. Anyone can } \\
\text { get it. }\end{array}$ \\
\hline Concerned about weight & 2 & $\begin{array}{l}\text { It just motivates me to do better for myself in regards to } \\
\text { watching what I eat. }\end{array}$ \\
\hline CDS level & 21 & \\
\hline PCP used the CDS during the visit with the patient & 17 & $\begin{array}{l}\text { We looked at it together ... and he says, "Yes. Your last } \\
\text { one was a long time ago." He said, "so we better schedule } \\
\text { you another one." }\end{array}$ \\
\hline Helped patients decide & 8 & $\begin{array}{l}\text { It did make me decide, but it also gave me the opportunity } \\
\text { to put it on my terms. }\end{array}$ \\
\hline Prompted patient/PCP cancer prevention discussion & 8 & $\begin{array}{l}\text { Interviewer: Would you have [discussed cancer prevention] } \\
\text { otherwise if you didn't have that form? Subject: Not today. } \\
\text { It would have been one of those things I would have } \\
\text { forgotten about. }\end{array}$ \\
\hline Provided discussion guidelines & 4 & $\begin{array}{l}\text { It kind of gave a little bit of a guideline. We had a lot to talk } \\
\text { about. So yeah, it was ... nice to have on the way out. }\end{array}$ \\
\hline Physical printout made problems real for patients & 2 & $\begin{array}{l}\text { That's why I hate going to the doctor ... and then you get } \\
\text { the paper that you basically, you know, life is really a hot } \\
\text { mess on paper. ... When you see it on paper, it's real. }\end{array}$ \\
\hline Barriers & 25 & \\
\hline Patient level & 18 & \\
\hline Did not want to talk about cancer prevention & 12 & $\begin{array}{l}\text { I've had cervical cancer twice so I don't want to talk about } \\
\text { [cancer prevention] anymore. }\end{array}$ \\
\hline Not concerned about cancer prevention or risk & 5 & $\begin{array}{l}\text { I don't have a big family history of it. ... We don't have any } \\
\text { breast cancer or anything like that, so l've never really } \\
\text { worried too much about it. }\end{array}$ \\
\hline Negative prior experience with screening & 4 & $\begin{array}{l}\text { Through the years, I skipped because my very first } \\
\text { [mammogram] hurt. }\end{array}$ \\
\hline Deferred decision on cancer prevention and screening & 4 & $\begin{array}{l}\text { When I come in next week, l'll talk to whoever my provider } \\
\text { is. ... We can discuss it. We'll see. }\end{array}$ \\
\hline Not ready to quit smoking & 3 & $\begin{array}{l}{[P C P] \text { just had asked if I was ready to quit, and I'm not }} \\
\text { ready to do that. }\end{array}$ \\
\hline Not willing to address weight & 2 & $\begin{array}{l}\text { I'm over the weight. Listen, I don't care about that } \\
\text { anymore. }\end{array}$ \\
\hline Misconception about cancer screening & 1 & $\begin{array}{l}\text { It seems like everyone that l've met that has gotten a } \\
\text { mammogram ends up with cancer. So that's why I don't } \\
\text { want to do it. }\end{array}$ \\
\hline \multicolumn{3}{|l|}{ CDS level } \\
\hline PCP did not use CDS with the patient during the visit & 8 & $\begin{array}{l}\text { [PCP] just said that this was the first time it's happened } \\
\text { here [the CDS being printed] and she wasn't real familiar } \\
\text { with it either. }\end{array}$ \\
\hline
\end{tabular}

Note: Interviewees could be included under more than one subtheme.

CDS, clinical decision support; $P C P$, primary care provider. 
Table 4. CDS-Recommended Cancer Prevention and Screenings, Visit Discussions, and Decisions Made Reported by Interviewees $(n=37)$

\begin{tabular}{|c|c|c|c|c|c|c|}
\hline Type & $\mathbf{n}$ & $\begin{array}{l}\text { Total } \\
\text { discussed at } \\
\text { visit, } \mathrm{n}(\%)\end{array}$ & $\begin{array}{l}\text { Cancer screening } \\
\text { or prevention } \\
\text { performed or } \\
\text { scheduled }\end{array}$ & n (\%) & $\begin{array}{l}\text { Reasons why no cancer screening or } \\
\text { prevention performed or scheduled }\end{array}$ & n (\%) \\
\hline Breast & 13 & $10(77 \%)$ & To be scheduled & $4(31 \%)$ & $\begin{array}{l}\text { Did not choose screening (undecided) } \\
\text { Deferred to next visit } \\
\text { Already scheduled prior to visit } \\
\text { Recent screen at different system } \\
\text { Did not state choice } \\
\text { Against screening }\end{array}$ & $\begin{array}{c}2(15 \%) \\
2(15 \%) \\
2(15 \%) \\
1(8 \%) \\
1(8 \%) \\
1(8 \%)\end{array}$ \\
\hline Cervical & 14 & $9(64 \%)$ & $\begin{array}{l}\text { Pap performed } \\
\text { To be scheduled }\end{array}$ & $\begin{array}{l}5(36 \%) \\
4(29 \%)\end{array}$ & $\begin{array}{c}\text { Did not choose screening (undecided) } \\
\text { Deferred to next visit } \\
\text { Pap scheduled prior } \\
\text { Recent screen at different system }\end{array}$ & $\begin{array}{c}2(14 \%) \\
1(7 \%) \\
1(7 \%) \\
1(7 \%)\end{array}$ \\
\hline Colorectal & 15 & $13(87 \%)$ & $\begin{array}{l}\text { To be scheduled } \\
\text { Has FIT test at home }\end{array}$ & $\begin{array}{l}5(38 \%) \\
1(8 \%)\end{array}$ & $\begin{array}{c}\text { Recent screen at different system } \\
\text { Did not choose screening (undecided) } \\
\text { Deferred to next visit } \\
\text { Against screening }\end{array}$ & $\begin{array}{c}4(27 \%) \\
3(20 \%) \\
1(7 \%) \\
1(7 \%)\end{array}$ \\
\hline HPV & 4 & $3(75 \%)$ & Received vaccine & $1(25 \%)$ & $\begin{array}{c}\text { Against vaccine } \\
\text { Did not choose vaccination (undecided) }\end{array}$ & $\begin{array}{l}2(50 \%) \\
1(25 \%)\end{array}$ \\
\hline Lung & 12 & $1(8 \%)$ & To be scheduled & $1(8 \%)$ & $\begin{array}{c}\text { Did not choose screening (undecided) } \\
\text { Deferred to next visit } \\
\text { Recent screen at different system }\end{array}$ & $\begin{array}{c}7(58 \%) \\
3(25 \%) \\
1(8 \%)\end{array}$ \\
\hline
\end{tabular}

Note: Participants could have more than one cancer screening and prevention need.

CDS, clinical decision support; FIT, fecal immunochemical test; HPV, human papillomavirus.

Some participants had already had the recommended screening outside the health system, with the CDS acting as a prompt for updating the electronic health record with accurate information. Others simply did not decide on cancer screening or prevention at the visit. Regarding use of the CDS in decision-making, only $1(13 \%)$ of the 8 participants who reported not reviewing the CDS with their PCP also reported deciding to either schedule or complete cancer prevention and screening items (data not shown in Table 4). Conversely, 10 (59\%) of the 17 participants who reported reviewing the CDS with their PCP decided to be screened or take preventive measures. It was unclear in the interviews if the remaining 12 respondents reviewed the CDS with their provider.

\section{DISCUSSION}

We conducted qualitative interviews with adults due or overdue for cancer prevention and screening at intervention primary care clinics participating in a cluster-randomized controlled trial of personalized CDS. Participants noted many strengths of the CDS while providing opportunities for improvement. We found that the reported facilitators and barriers to cancer prevention decision-making were primarily at the patient level. While participants also noted multiple CDS-level facilitators, the only CDS-level barrier was lack of some PCPs using the CDS with patients. This may be a product of the interview focus or could relate to PCP-perceived time limitations. ${ }^{15,16,21,23}$

The personal importance of cancer prevention and screening to patients seems to be a critical facilitator in decision-making, likely the result of successful health system and government prevention education efforts, particularly for common screenings like mammography, colonoscopy, and Pap tests. While many participants reported making some sort of decision during their visit, our findings suggest that knowledge on lung cancer screening for those eligible may be lacking. Tools like the CDS may help with this knowledge gap; however, PCP buy-in and understanding of the risks and benefits of lowdose computed tomography scans are likely necessary for patients and PCPs to make a shared decision regarding lung cancer screening. ${ }^{43}$ 
PCPs report not having enough time to go over decision aids alongside patients. ${ }^{15}$ Yet, participants in this study appeared to value the personalized recommendations of the CDS in decision-making, including with PCPs, findings supported by previous research that illustrated the benefits of PCPs using decision aids with patients. ${ }^{17}$ Furthermore, our finding that most participants wanted to discuss cancer screening and prevention at their visit is consistent with previous research showing overwhelming support for cancer screening. ${ }^{11}$ Concerns about PCP time limitations may be allayed by recognizing how patients appreciate the CDS. ${ }^{19}$

PCPs may want to place higher weight on patient preferences and needs when considering adopting decision aids and CDS into practice. The participants in this exploratory qualitative study appeared to be influenced in their decision-making by PCPs who used the CDS, with those who actually discussed the CDS with their PCP reporting making more decisions about cancer screening and prevention than those who did not. This suggests the value of SDM between patient and PCP with tools like the CDS as well as the influence that PCPs have in aiding patients with decision-making, ${ }^{25,26}$ which research such as our larger randomized controlled trial can better assess.

PCPs may benefit from additional training in SDM and patient engagement in order for CDS interventions to be widely adopted into clinical practice ${ }^{35}$ More responsibility for using the CDS could also be moved to other team members like medical assistants. ${ }^{44}$ Preimplementation, qualitative interviews with key health system informants showed that many saw CDS benefits for patients: time savings, education, controlling health, reminders, and exposure to cancer prevention and screening recommendations. ${ }^{21}$

\section{Limitations}

This study did have limitations. Participants were primarily White, female, and high school-educated (or more) and were seen in a primary care clinic within a single health system. Interviews also focused only on patient perceptions. Future research could examine the experiences of PCPs alongside patients using CDS tools. In addition, our study did not explore PCP-level barriers to cancer prevention and screening, as outside of CDS use, these were not noted by participants. Other research is available on PCP-level barriers to using CDS. ${ }^{15,16,45}$ Furthermore, we only captured participants' intentions, not whether they followed through with items that could not be completed during their visit. However, interviewing participants immediately following their visit with their PCP limited recall bias.
We could not determine from participant responses to interview questions whether 12 patients reviewed the CDS with their PCP or not. Our findings related to decision-making and CDS use between patients and PCPs are exploratory, as is the study outlined in this paper. More research is needed on what actually happens within clinic visits using CDS systems. We also do not know how many patients were approached by rooming staff to take part in the study or how many declined. We did initially keep track of patients who were eligible for the CDS due to having one or more uncontrolled cardiovascular risk factors but did not have any CDS areas related to cancer screening and prevention. Instead, we trained the rooming staff to only invite patients to participate if they were overdue for a cancer screening and prevention item.

Lastly, the CDS system was available for all office visits, not only for annual exams, where patient-presenting problems were likely the focus of the visit rather than cancer prevention and screening.

\section{CONCLUSIONS}

In individual interviews, adults due or overdue for breast, cervical, colorectal, or lung cancer screening or HPV vaccination described many benefits of an individually tailored CDS tool, including around decision-making. Use of the CDS with patients within a primary care visit may positively assist shared decision-making, providing experiential evidence of the value of CDS for both patients and PCPs when making shared cancer prevention and screening decisions.

Our qualitative findings highlight the importance of getting information into patients' hands, including for facilitating SDM. The CDS appears to engage and inform patients on cancer prevention and screening, which may help them become more involved with their own health care. Patients having personal access to CDS may be particularly important, as we found some participants reported their PCP did not utilize the CDS with them.

Future research could examine whether patients prefer to receive their CDS in advance of their PCP visit through an online patient portal or during their visit. With the nationwide adoption of virtual visits spurred by the COVID-19 pandemic, ${ }^{46}$ CDS can be adapted for use in electronic formats, such as within online patient portals. Future research could examine the effectiveness of CDS within virtual visits. CDS systems also have the potential for greater scalability in primary care and beyond. 


\section{Patient-Friendly Recap}

- A clinical decision support (CDS) tool linked to the electronic health record might help patients decide whether or not to undergo recommended cancer screening and prevention.

- Authors qualitatively analyzed interviews with 37 primary care patients to learn their perspectives regarding point-of-care CDS content. While areas for improving the tool were identified, some participants reported it helped them make a decision they otherwise would not have made.

- A personalized CDS tool for cancer screening and prevention was found to be useful and a beneficial addition to office visits. However, many primary care providers did not use the tool with eligible patients.

\section{Acknowledgments}

We thank the Essentia Health primary care clinic staff for their assistance with this study.

\section{Author Contributions}

Study design: Saman, Harry, O’Connor, Sperl-Hillen, Bianco, Truitt, Elliott. Data acquisition or analysis: Saman, Harry, Freitag, Allen. Manuscript drafting: Saman, Harry, Freitag. Critical revision: Allen, O’Connor, Sperl-Hillen, Truitt, Ekstrom, Elliott.

\section{Conflicts of Interest}

None.

\section{Funding Sources}

This research was funded by the National Institutes of Health/ National Cancer Institute (grant number R01CA193396).

\section{References}

1. U.S. Cancer Statistics Working Group. United States Cancer Statistics: data visualizations, based on 2019 submission data (1999-2017) released in June 2020. U.S. Department of Health and Human Services, Centers for Disease Control and Prevention, National Cancer Institute. Accessed February 12, 2021. www.cdc.gov/cancer/dataviz

2. Lentz R, Benson AB 3rd, Kircher S. Financial toxicity in cancer care: prevalence, causes, consequences, and reduction strategies. J Surg Oncol. 2019;120:85-92. CrossRef

3. Glode AE, May MB. Rising cost of cancer pharmaceuticals: cost issues and interventions to control costs. Pharmacotherapy. 2017;37:85-93. CrossRef

4. Meites E, Kempe A, Markowitz LE. Use of a 2-dose schedule for human papillomavirus vaccination - updated recommendations of the advisory committee on immunization practices. $M M W R$ Morb Mortal Wkly Rep. 2016;65:1405-8. CrossRef

5. Moyer VA; U.S. Preventive Services Task Force. Screening for lung cancer: U.S. Preventive Services Task Force recommendation statement. Ann Intern Med. 2014;160:330-8. CrossRef
6. U.S. Preventive Services Task Force. Final recommendation statement. Breast cancer: screening. Published January 11, 2016; accessed February 12, 2021. https://uspreventiveservicestaskforce. org/Page/Document/RecommendationStatementFinal/breastcancer-screening 1

7. U.S. Preventive Services Task Force. Final recommendation statement. Colorectal cancer: screening. Published June 16, 2016; accessed February 12, 2021. https://uspreventiveservicestaskforce. org/uspstf/document/RecommendationStatementFinal/colorectalcancer-screening

8. U.S. Preventive Services Task Force. Final recommendation statement. Cervical cancer: screening. Published August 21, 2018; accessed February 12, 2021. https://uspreventiveservicestaskforce. org/uspstf/document/RecommendationStatementFinal/cervicalcancer-screening

9. Gail MH, Brinton LA, Byar DP, et al. Projecting individualized probabilities of developing breast cancer for projecting individualized probabilities of developing breast cancer for white females who are being examined annually. J Natl Cancer Inst. 1989;81:1879-86. CrossRef

10. National Cancer Institute. The Breast Cancer Risk Assessment Tool. Accessed May 13, 2021. https://bcrisktool.cancer.gov

11. Torke AM, Schwartz PH, Holtz LR, Montz K, Sachs GA. Older adults and forgoing cancer screening: "I think it would be strange." JAMA Intern Med. 2013;173:526-31. CrossRef

12. Carter-Harris L, Brandzel S, Wernli KJ, Roth JA, Buist DSM. A qualitative study exploring why individuals opt out of lung cancer screening. Fam Pract. 2017;34:239-44. CrossRef

13. Sheridan SL, Harris RP, Woolf S. Shared decision making about screening and chemoprevention: a suggested approach from the U.S. Preventive Services Task Force. Am J Prev Med. 2004;26:56-66. CrossRef

14. Joosten EA, DeFuentes-Merillas L, de Weert GH, Sensky T, van der Staak CPF, de Jong CAJ. Systematic review of the effects of shared decision-making on patient satisfaction, treatment adherence and health status. Psychother Psychosom. 2008;77:219-26. CrossRef

15. Waldron T, Carr T, McMullen L, et al. Development of a program theory for shared decision-making: a realist synthesis. BMC Health Serv Res. 2020;20(1):59. CrossRef

16. Yahanda AT, Mozersky J. What's the role of time in shared decision making? AMA J Ethics. 2020;22:E416-22. CrossRef

17. Stacey D, Légaré F, Lewis K, et al. Decision aids for people facing health treatment or screening decisions. Cochrane Database Syst Rev. 2017;4(4):CD001431. CrossRef

18. Trikalinos TA, Wieland LS, Adam GP, Zgodic A, Ntzani EE. Decision aids for cancer screening and treatment [internet]. Agency for Healthcare Research and Quality (US); 2014 December, comparative effectiveness reviews no. 145, report no. 15-EHC002-EF.

19. Berner ES. Clinical decision support systems: state of the art [Agency for Healthcare Research and Quality publication no. 090069-EF]. Published June 2009; accessed February 12, 2021. http:// healthit.ahrq.gov/sites/default/files/docs/page/09-0069-EF 1.pdf

20. Osheroff JA, Teich JM, Levick D, et al. Improving Outcomes With Clinical Decision Support: An Implementer's Guide, Second Edition. CRC Press; 2012.

21. Harry ML, Truitt AR, Saman DM, et al. Barriers and facilitators to implementing cancer prevention clinical decision support in primary care: a qualitative study. BMC Health Serv Res. 2019;19(1):534. CrossRef 
22. Saman DM, Walton KM, Harry ML, et al. Understanding primary care providers' perceptions of cancer prevention and screening in a predominantly rural healthcare system in the upper Midwest. BMC Health Serv Res. 2019;19(1):1019. CrossRef

23. Elliott TE, O'Connor PJ, Asche SE, et al. Design and rationale of an intervention to improve cancer prevention using clinical decision support and shared decision making: a clinicrandomized trial. Contemp Clin Trials. 2021;102:106271. $\underline{\text { CrossRef }}$

24. McAlpine K, Lavallée LT, Stacey D, et al. Development and acceptability testing of a patient decision aid for urinary diversion with radical cystectomy. J Urol. 2019;202:1001-7. CrossRef

25. Honein-AbouHaidar GN, Kastner M, Vuong V, et al. Systematic review and meta-study synthesis of qualitative studies evaluating facilitators and barriers to participation in colorectal cancer screening. Cancer Epidemiol Biomark Prev. 2016;25:907-17. CrossRef

26. Peterson EB, Ostroff JS, DuHamel KN, et al. Impact of provider-patient communication on cancer screening adherence: a systematic review. Prev Med. 2016;93:96-105. CrossRef

27. Bhuyan SS, Chandak A, Gupta N, et al. Patient-provider communication about prostate cancer screening and treatment: new evidence from the health information national trends survey. Am J Mens Health. 2017;11:134-46. CrossRef

28. Dunn AS, Shridharani KV, Lou W, Bernstein J, Horowitz CR. Physician-patient discussions of controversial cancer screening tests. Am J Prev Med. 2001;20:130-4. CrossRef

29. Guerra CE, Jacobs SE, Holmes JH, Shea JA. Are physicians discussing prostate cancer screening with their patients and why or why not? A pilot study. J Gen Intern Med. 2007;22:901-7. CrossRef

30. Han PKJ, Kobrin S, Breen N, et al. National evidence on the use of shared decision making in prostate-specific antigen screening. Ann Fam Med. 2013;11:306-14. CrossRef

31. Harry ML, Saman DM, Truitt AR, et al. Pre-implementation adaptation of primary care cancer prevention clinical decision support in a predominantly rural healthcare system. BMC Med Inform Decis Mak. 2020;20(1):117. CrossRef

32. Kwon HT, Ma GX, Gold RS, Atkinson NL, Wang MQ. Primary care physicians' cancer screening recommendation practices and perceptions of cancer risk of Asian Americans. Asian Pac J Cancer Prev. 2013;14:1999-2004. CrossRef

33. Brenner AT, Malo TL, Margolis M, et al. Evaluating shared decision making for lung cancer screening. JAMA Intern Med. 2018;178:1311-6. CrossRef
34. Hoffman RM, Lewis CL, Pignone MP, et al. Decision-making processes for breast, colorectal, and prostate cancer screening: the DECISIONS survey. Med Decis Mak. 2010;30:53S-64S. CrossRef

35. Légaré F, Witteman HO. Shared decision making: examining key elements and barriers to adoption into routine clinical practice. Health Aff (Millwood). 2013;32:276-84. CrossRef

36. Wagner EH. Chronic disease management: What will it take to improve care for chronic illness? Eff Clin Pract. 1998;1:2-4.

37. Sperl-Hillen JM, Rossom RC, Kharbanda EO, et al. Priorities Wizard: multisite web-based primary care clinical decision support improved chronic care outcomes with high use rates and high clinician satisfaction rates. EGEMS (Wash DC). 2019;7(1):9. CrossRef

38. Sperl-Hillen JM, Crain AL, Margolis KL, et al. Clinical decision support directed to primary care patients and providers reduces cardiovascular risk: a randomized trial. $J$ Am Med Inform Assoc. 2018;25:1137-46. CrossRef

39. O'Connor PJ, Sperl-Hillen JM, Rush WA, et al. Impact of electronic health record clinical decision support on diabetes care: a randomized trial. Ann Fam Med. 2011;9:12-21. CrossRef

40. Spratt JS. The primary and secondary prevention of cancer. J Surg Oncol. 1981;18:219-30. CrossRef

41. Researchware, Inc. HyperRESEARCH 4.5.0 software. Accessed February 12, 2021. http://researchware.com

42. Schreier M. Qualitative Content Analysis in Practice, 1st Edition. SAGE Publications; 2012.

43. Simmons VN, Gray JE, Schabath MB, Wilson LE, Quinn GP. High-risk community and primary care providers knowledge about and barriers to low-dose computed topography lung cancer screening. Lung Cancer. 2017:106;42-9. CrossRef

44. Bodenheimer T, Willard-Grace R, Ghorob A. Expanding the roles of medical assistants: Who does what in primary care? JAMA Intern Med. 2014;174:1025-6. CrossRef

45. Krelle H, Dodson JA, Horwitz L. Virtual primary care - is its expansion due to COVID-19 all upside? JAMA Health Forum. 2020;1(7):e200900. CrossRef

46. Eichner J, Das M; NORC at the University of Chicago. Challenges and barriers to clinical decision support (CDS) design and implementation experienced in the Agency for Healthcare Research and Quality CDS Demonstrations [AHRQ publication no. 10-0064-EF]. Published March 2010; accessed February 12, 2021. https://digital.ahrq.gov/sites/default/files/ docs/page/CDS_challenges_and_barriers.pdf

(C) 2021 Advocate Aurora Health, Inc. 